\title{
Computed Tomography-Guided Optical Sensor-Guided Radiofrequency Ablation
}

National Cancer Institute

\section{Source}

National Cancer Institute. Computed Tomography-Guided Optical Sensor-Guided

Radiofrequency Ablation. NCI Thesaurus. Code C116445.

The use of CT imaging to guide the placement of the electrode for radiofrequency ablation. 